\title{
Comparing Administration of Hospital Wastes Using Social Network Analysis
}

\author{
Mustafa Ali ${ }^{1}$, Wenping Wang ${ }^{1}$ and Nawaz Chaudhry ${ }^{2}$ \\ ${ }^{1}$ Department of Management Science \& Engineering, Southeast University, Nanjing, P.R. China \\ ${ }^{2}$ College of Earth \& Environmental Sciences, University of the Punjab, Lahore, Pakistan
}

\begin{abstract}
Waste management requires interaction between different players. It is important to map theses interactions to identify key players. This study utilizes social network analysis to compare the organization of waste management activities at two different hospitals. One of these hospitals was a large public hospital whereas the other one was a small private hospital. The structure and characteristics of the waste management network varied at both hospitals. On the whole the network at the larger hospital was institutional and the one at the smaller hospital was social in nature. At the larger hospital communication between any two members on average required three degrees of freedom. Moreover, its waste management network was characterized by the presence of three brokers whose absence could split the network into smaller disparate components. At the smaller hospital the waste management activities suffered from a lack of involvement from the paramedic staff. Thus its waste management network was more compact and communication between most of the network members did not require an intermediary. In both hospitals, a feedback mechanism between the municipal sanitary staff and hospital management was conspicuous by its absence. Hence issues such as an incidence of hazardous items mixed in the general waste could not be communicated to the hospital directly. The key positions identified in this study can be used for behavioral changes related to waste management among the concerned hospital staff.
\end{abstract}

\section{Introduction}

Health care activities can result in different kinds of waste. Mismanagement of these wastes can result in environmental and occupational health risks. It is important to analyze healthcare waste management (HWM) activities as this can help us gain a clearer picture of the situation on the ground and identify areas of improvement [1]. Most of the studies in existing literature focus only on the waste generation rates [2], behavior regarding waste management activities [3] or compliance with regulations [4]. Such studies fail to account for the complex interactions between the different people involved in waste management activities. With advancements in data mining softwares it is now possible to map these interactions in a graphical format [5]. This study involves an investigation of the waste management structure at two hospitals in Gujranwala, a major city of Pakistan. Here we employed Social Network Analysis (SNA) [6] as this approach leads to more information than afforded by organizational flow charts. It provides a clear advantage in identifying the influencers and opinion leaders in an institutional setting. Such positions can be exploited for monitoring, evaluation and change, if necessary. Existing models to investigate healthcare waste management structures employ techniques such as system dynamics [7], total quality management [8], life cycle analysis [9], etc. Few studies employing SNA on HWM can be found in the existing literature. Those that do exist, focus on the socioeconomic interactions between a wide array of stakeholders [10]. Examining the internal waste management architecture at the hospitals is not their goal or purpose. Hence this study aims to fill a gap by focusing on the internal waste management interactions at the hospitals from a SNA perspective.

\section{Methodology}

The study was conducted between September 2014 and January 2015 at the two hospitals. One of these (H1) was the largest and the only public hospital in the city. The other hospital (H2) was a small private hospital with 37 beds. The latter represented the majority of the hospitals in the city which were also small and privately owned. The hospital staff involved in waste management activities were interviewed regarding their daily interactions. The composition of the staff was determined after visiting the hospitals and interviewing staff members and hospital administration regarding their daily interactions. Consequently at $\mathrm{H} 1$ the relevant staff included members of the hospital waste management team, the hospital sanitary workers, the nurses, the municipal sanitary workers, the scavengers and a 
commercial firm charged with incineration of the medical wastes. At $\mathrm{H} 2$ these staff consisted of the Admin Manager, the Waste Manager, the Matron, ward boys, sanitary staff, the commercial firm and a scavenger. Each of these staff members was asked about her/his communications with staff from the same or other hospitals or clinics, laboratories, municipality, NGOs, scavengers, the local waste management company and the commercial firm. The study was conducted in the form of a questionnaire survey. Most of the sanitary staff were illiterate and hence they were directly interviewed by the first author. The response items included the names of the people, the frequency of interactions, the direction of communication between them and their category. The networks were constructed and analyzed using Gephi 0.8.2 [11].

\section{Results \& Discussion}

Fig. 1 and 2 represent the social network diagrams of waste segregation, collection and transportation activities at $\mathrm{H} 1$ and $\mathrm{H} 2$ respectively. The size of each node represents its relative influence and the thickness of the links/edges between two nodes represents the frequency of their interactions. For simplicity purposes the networks have been considered to be undirected.

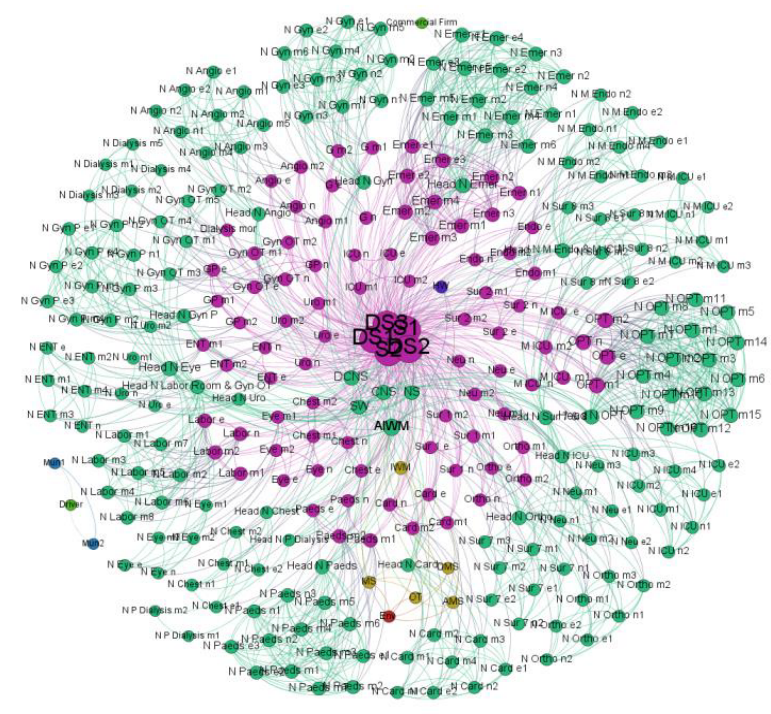

Figure 1. Waste management network at $\mathrm{H} 1$.

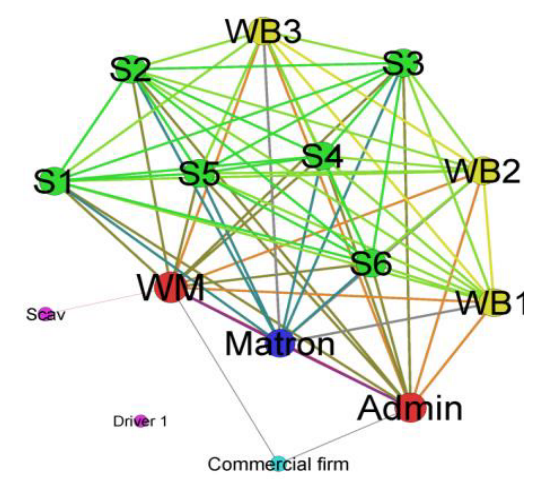

Figure 2. Waste management network at $\mathrm{H} 2$.
Both hospitals had constituted a waste management team in compliance with national regulations regarding safe management of hospital wastes. At $\mathrm{H} 1$ this team consisted of the medical superintendant, the deputy medical superintendant, a waste management in-charge, an assistant waste management in-charge, a doctor from the operation theatre, the environmental officer and the assistant medical superintendant. Waste segregation in each ward was conducted by the nursing staff whereas its collection was carried out by a sanitary worker specially assigned for this work. The disposal of the medical waste was carried out by a commercial firm. A lack of connections between the commercial firm and the waste management team or the sanitary supervisors at $\mathrm{H} 1$ represents a shortcoming in this network. Transportation of the general waste from the wards was carried out by the hospital sanitary staff. This waste was usually thrown around a municipal waste container by the hospital sanitary staff. The municipal sanitary staff, later, loaded it inside the container. The filled container was towed away to an open landfill site by a municipal waste truck, where it was subsequently emptied. The link between the driver of the municipal truck and the municipal sanitary staff represents the second component in the network at $\mathrm{H} 1$. No formal link existed between the two components. This highlights a lack of any feedback mechanism between the hospital management and the municipal sanitary staff. Hence any issues such as the presence of hazardous items in the general waste could not be directly communicated to the hospital. At $\mathrm{H} 2$ the waste management team consisted of the Admin Manager, the Waste Manager and the Matron. Source segregation of the hospital waste wasn't practiced and hence as opposed to H1, the nurses did not play any role in the waste management activities here. Moreover, there was no clear distinction between the roles of the ward boys and the sanitary workers. The male sanitary workers also acted as the ward boys while the female sanitary staff only handled sanitary operations. In Figure 2 the three ward boys at $\mathrm{H} 2$ are represented as WB1, WB2 and WB3 while the five female sanitary staff members are represented as $\mathrm{S} 1$ through S5. At $\mathrm{H} 2$, the waste was transported by the hospital sanitary staff to two wall mounted drums in a side street. A scavenger collected the wastes from the drums each morning and carried them to the nearest municipal container on his donkey cart. The waste from this container was collected twice a week by a municipal truck, represented by driver 1 in Figure 2. This waste was also thrown in the open land fill site. The municipal waste collector did not have any link with other members of the network at $\mathrm{H} 2$ and thus it is represented as an independent component. Table 1. provides the descriptive statistics [12] for the HWM network at $\mathrm{H} 1$ and $\mathrm{H} 2$.

The Table 1 shows that at $\mathrm{H} 1$ every member of the waste management network was connected to almost 13 people on average while at $\mathrm{H} 2$ the average degree was 9 . The network density shows that the interactivity in the network at $\mathrm{H} 1$ was low as only $4.5 \%$ of all possible connections were actually realized. In contrast the network at $\mathrm{H} 2$ was highly social in nature as $65.7 \%$ of all possible connections were in existence. The diameter reveals that, on average, each person at $\mathrm{H} 1$ was 4 steps 
removed from her/his colleagues whereas at $\mathrm{H} 2$ the average distance was just 2. The average path length indicates that at $\mathrm{H} 1$ on average it would only take 3 ties to go from one member to another in the network. The average length at $\mathrm{H} 2$ was only 1 . The average clustering coefficient at $\mathrm{H} 1$ had a value of $73 \%$ as compared to a value of $96.7 \%$ at $\mathrm{H} 2$. This shows that network members at $\mathrm{H} 2$ could relatively easily approach their colleagues. In essence, this information demonstrates that the network at $\mathrm{H} 1$ was institutional rather than social in nature. Moreover, a few powerful nodes existed that could control the flow of information in both directions. At $\mathrm{H} 2$ the network was highly social in nature as all nodes could easily approach each other. The removal of any node at $\mathrm{H} 2$ could not break the network into independent segments. Table 2. ranks the relative influence of the different nodes according to the metrics of degree, centrality and clustering coefficient [13]. Here, the degree of a node represents the number of direct connections it has with rest of the nodes in the network. Similarly, closeness centrality shows how far a person is from the others in a network, betweenness centrality shows the frequency with which a node forms a bridge between two others and Eigen vector centrality measures the centrality of a node relative to the centralities of its neighbors. The clustering coefficient is a ratio between the number of connections a node has and the total number of possible connections it could have. Thus clustering coefficient shows if the node is utilizing the full potential of its position by connecting to as many other nodes as possible.

Table 1. Descriptive statistics for hospital waste management network.

\begin{tabular}{|l|r|r|}
\hline Measure & \multicolumn{1}{|l|}{ H1 } & \multicolumn{1}{l|}{ H2 } \\
\hline No. of nodes & 296 & 15 \\
\hline No. of edges & 1978 & 69 \\
\hline Average degree & 13.36 & 9.2 \\
\hline Minimum & 1 & 1 \\
\hline Maximum & 94 & 10 \\
\hline Network density & $4.5 \%$ & $65.7 \%$ \\
\hline Diameter & 4 & 2 \\
\hline Average path length & 3.07 & 1.24 \\
\hline Average clustering coefficient & $73.2 \%$ & $96.7 \%$ \\
\hline
\end{tabular}

The Table 2 shows that at $\mathrm{H} 1$ the sanitary supervisors and deputy supervisors had the most influential and central position in the network. On the other hand the commercial firm and the nurses working in the private dialysis ward (Nurse Pvt Dialysis) were the farthest away from others in the network. Among the waste management team only the assistant waste management in-charge (AIWM) had a high degree and betweenness centrality. It was learnt that the position of AIWM was held by a nurse. Thus she represented a vital link between the management, the nurses and the sanitary supervisors. Interestingly the sanitary workers in the operation theatre (Sanitary OPT) also had some of the highest degrees in the network. However they did not have high centralities relative to the others. The sanitary workers in the ICU ward (Sanitary ICU) and members of the waste management team were linked with all the possible connections they could have and thus they had the highest clustering coefficients in the network. At $\mathrm{H} 2$ the waste management team members had the highest degrees and network centralities. The scavenger and the commercial firm were the furthest away from other members of the network. Except for the Waste Manager, the Admin Manager and the scavenger every node in the network had a clustering coefficient of $100 \%$. Thus most of the members had realized all the possible connections they could have.

Table 2. Ranking of nodes in hospital waste management network.

\begin{tabular}{|c|c|c|c|c|c|}
\hline \multirow[t]{2}{*}{$\begin{array}{l}\text { Ra } \\
\text { nk }\end{array}$} & \multirow[t]{2}{*}{ Degree } & \multicolumn{3}{|l|}{ Centrality } & \multirow[t]{2}{*}{$\begin{array}{l}\text { Clustering } \\
\text { Coefficient } \\
\end{array}$} \\
\hline & & Closeness & $\begin{array}{l}\text { Between } \\
\text { ness }\end{array}$ & $\begin{array}{l}\text { Eigen } \\
\text { Vector } \\
\end{array}$ & \\
\hline \multicolumn{6}{|c|}{ (H1) } \\
\hline 1 & $\begin{array}{l}\text { Supervis } \\
\text { or } 1\end{array}$ & $\begin{array}{l}\text { Nurse Pvt } \\
\text { Dialysis }\end{array}$ & $\begin{array}{l}\text { Supervis } \\
\text { or } 1\end{array}$ & $\begin{array}{l}\text { Dep } \\
\text { Supervis } \\
\text { or } 2\end{array}$ & $\begin{array}{l}\text { Sanitary } \\
\text { ICU }\end{array}$ \\
\hline 2 & $\begin{array}{l}\text { Supervis } \\
\text { or } 2\end{array}$ & $\begin{array}{l}\text { Nurse Pvt } \\
\text { Dialysis }\end{array}$ & $\begin{array}{l}\text { Supervis } \\
\text { or } 2\end{array}$ & $\begin{array}{l}\text { Supervis } \\
\text { or 1 }\end{array}$ & $\begin{array}{l}\text { Sanitary } \\
\text { ICU }\end{array}$ \\
\hline 3 & $\begin{array}{l}\text { Dep } \\
\text { Supervis } \\
\text { or 1 } \\
\end{array}$ & $\begin{array}{l}\text { Commerc } \\
\text { ial Firm }\end{array}$ & $\begin{array}{l}\text { Dep } \\
\text { Supervis } \\
\text { or 1 }\end{array}$ & $\begin{array}{l}\text { Supervis } \\
\text { or } 2\end{array}$ & $\begin{array}{l}\text { Sanitary } \\
\text { ICU }\end{array}$ \\
\hline \multicolumn{6}{|c|}{$(\mathrm{H} 2)$} \\
\hline 1 & $\begin{array}{l}\text { Waste } \\
\text { Manager }\end{array}$ & Scavenger & $\begin{array}{l}\text { Waste } \\
\text { Manager }\end{array}$ & $\begin{array}{l}\text { Waste } \\
\text { Manager }\end{array}$ & Matron \\
\hline 2 & $\begin{array}{l}\text { Admin } \\
\text { Manager }\end{array}$ & $\begin{array}{l}\text { Commerc } \\
\text { ial Firm }\end{array}$ & $\begin{array}{l}\text { Admin } \\
\text { Manager }\end{array}$ & $\begin{array}{l}\text { Admin } \\
\text { Manager }\end{array}$ & Ward Boy 1 \\
\hline 3 & Matron & Matron & - & Matron & Ward Boy 2 \\
\hline
\end{tabular}

\section{Conclusions}

This study represents the organization of waste management activities at two hospitals. One of these, H1, had a centralized structure Lack of formal connections between the commercial firm and the hospital waste management team was discovered as one of the weaknesses of this network. At $\mathrm{H} 2$ the network was highly social and thus not susceptible to division in the absence of a node. The absence of source segregation at $\mathrm{H} 2$ displayed a weakness in the network structure as it eliminated the role of the nursing staff in waste management activities. Lack of connections between the municipal sanitary staff and the hospital management at both hospitals also represented a weakness as there was no alternate feedback mechanism between these components. This study can be used by managers for the formation of a more resilient waste management structure which includes all relevant actors. Policy makers can use this study as a stepping stone for further research into the organization of infectious waste management at different healthcare facilities.

\section{Acknowledgment}

The writers would like to acknowledge the support extended by Major Program of the National Social Science Foundation of China [12\&ZD207].

\section{References}


1. B. Sapkota, G. K. Gupta, D. Mainali, Impact of intervention on healthcare waste management practices in a tertiary care governmental hospital of Nepal, Bmc Public Health 14, (2014)

2. R. Gai, C. Kuroiwa, L. Xu, X. Wang, Y. Zhang, H. Li, et al., Waste Manag Res 27, 336-42(2009)

3. P. Lakbala, M. Lakbala, Knowledge, attitude and practice of hospital staff management, Waste Manag Res. 31, 729-32 (2013)

4. M. A. Patwary, W. T. O'Hare, M. H. Sarker, An illicit economy: scavenging and recycling of medical waste, J Environ Manage 92, 2900-6 (2011)

5. J. N. Hall, S. Moore, A. Shiell, Assessing the congruence between perceived connectivity and network centrality measures specific to pandemic influenza preparedness in Alberta, Bmc Public Health 10, (2010)

6. L. Chauvel, A. K. Leist, Social Epidemiology, In: Wright JD, editor. International Encyclopedia of the Social \& Behavioral Sciences (Second Edition). Oxford: Elsevier, (275-81) (2015)
7. M. Chaerul, M. Tanaka, A. V. Shekdar, A system dynamics approach for hospital waste management. Waste Manag 28, (442-9) (2008)

8. M. Askarian, P. Heidarpoor, O. Assadian, A total quality management approach to healthcare waste management in Namazi Hospital, Iran. Waste Manag 30, (2321-6) (2010)

9. S. R. Soares, A. P. Finotti, V. P. da Silva, R. A. Alvarenga, Applications of life cycle assessment and cost analysis in health care waste management, Waste Manag 33, (175-83) (2013)

10. M. Caniato, T. Tudor, M. Vaccari, Understanding the perceptions, roles and interactions of stakeholder networks managing health-care waste: A case study of the Gaza Strip, Waste Manag 35, (255-64) (2015)

11. M. Salter-Townshend, A. White, I. Gollini, T.B. Murphy, Review of statistical network analysis: models, algorithms, and software, Statistical Analysis and Data Mining 5, (243-64) (2012)

12. J. Holt-Lunstad, Social Integration, Social Networks, and Health. Wright JD, editor. Oxford: Elsevier; (365-70) (2015)

13. J. Scott, Social network analysis: Sage, (2012) 